\title{
Reaction-based reactive transport modeling of $\mathrm{Fe}(\mathrm{III})$ 1024848
}

Argonne National Laboratory: K. M. Kemner*, and S. D. Kelly (Argonne National Laboratory, Biosciences Division, 9700 South Cass Avenue, Argonne, Illinois, 60439, Kemner@anl.gov (630) 252-1163)

The Pennsylvania State University: Bill Burgos

\section{University of Wisconsin, Madison: Eric Roden}

Research Objective: This research project (started Fall 2004) was funded by a grant to Argonne National Laboratory, The Pennsylvania State University, and The University of Alabama in the Integrative Studies Element of the NABIR Program (DE-FG04-ER63914/63915/63196). Dr. Eric Roden, formerly at The University of Alabama, is now at the University of Wisconsin Madison. Our project focuses on the development of a mechanistic understanding and quantitative models of coupled Fe(III)/U(VI) reduction in FRC Area 2 sediments. This work builds on our previous studies of microbial Fe(III) and U(VI) reduction, and is directly aligned with the Scheibe et al. NABIR FRC Field Project at Area 2.

Research Progress and Implications: This report summarizes work during FY2005 and FY 2006 (i.e., the first 2 years of a 3 year project). Limited background information about the project, as it relates to work performed at Argonne National Laboratory, is included to better explain the contributions by Argonne National Laboratory staff.

\section{Sorption and Bioreduction of Solid-Associated U(VI)}

The sorption of U(VI) to a series of specimen minerals found in FRC sediments has been measured and modeled. Adsorption isotherm experiments were conducted with U(VI) and amorphous aluminum hydroxide, crystalline gibbsite, activated alumina and illite clay, in the presence and absence of humic substances. The molecular coordination environment of sorbed $\mathrm{U}(\mathrm{VI})$ was evaluated by extend $\mathrm{x}$-ray absorption fine structure (EXAFS). U LIII-edge EXAFS measurements were made on these samples at the MRCAT/EnviroCAT insertion device beam line at the Advanced Photon Source. Cryo laser-induced fluorescence spectroscopy (CLIFS) measurements were also made on these samples at the Pacific Northwest National Laboratory. These spectroscopic evaluations revealed that solid-phase U(VI) was located in different molecular environments based on the mineral sorbent phase. A detailed comparison of the results from these two spectroscopic techniques will be the focus of an upcoming manuscript. We are currently running a series of experiments on the bioreducibility/bioavailability (using Geobacter sulfurreducens) of these U(VI)-loaded minerals. Incorporation of results of U LIIIedge EXAFS measurements of these samples (to be made in FY07) into an upcoming manuscript will be the focus of some of the Argonne National Laboratory staff in FY07.

Kinetics of U(VI) Reduction and U(IV) Oxidation

A series of experiments were designed to vary the rate of $U(V I)$ bioreduction to then characterize the reactivity of the different $\mathrm{U}(\mathrm{IV})$ solids produced (presumably biogenic uraninite).

Experiments were conducted with variable concentrations of Shewanella putrefaciens $\mathrm{CN} 32$ in a 
$30 \mathrm{mM}$ NaHCO3 buffer with $1 \mathrm{mM} \mathrm{U}(\mathrm{VI})$ and $5 \mathrm{mM}$ lactate. U(VI) was reduced at "slow", "medium" and "fast" rates (varied over 1 order of magnitude). The reduced U(IV) solids were subjected to re-oxidation by oxygen, iron(III), nitrite, nitrite plus Fe(II), and Thiobacillus denitrifcans (coupled to nitrate reduction). For all oxidants, U(IV) solids that were produced at a "fast" rate were most rapidly re-oxidized. The reduced U(IV) solids were examined with U LIIIedge EXAFS at the MRCAT/EnviroCAT insertion device beam line at the Advanced Photon Source. Results from these experiments revealed that molecular structure and particle size of the solids were directly related to the bioreduction rate. These samples have been analyzed by transmission electron microscopy (TEM) at the Environmental Molecular Science Laboratory to further characterize their physical associations with the bacteria. The field-scale implication of these findings is that electron donor addition that promotes the "slow" reduction of U(VI) may also produce U(IV) solids that are more stable with respect to re-oxidation. A manuscript summarizing these findings is in preparation and will be submitted for publication in FY07.

\section{Planned Activities:}

Long-term Area 2 Sediment Column Experiments A series of columns (6 total) packed with sediments collected from Area 2 at the Field Research Center (FRC) have been in operation for nearly one year. No attempt was made to sterilize the sediment and experiments were designed to stimulate the native microbial community by ethanol addition (as conducted in field studies). An artificial groundwater designed to match the solution chemistry at Area 2 is continuously pumped through the columns at a single, constant flow rate equivalent to 0.05 pore volumes/day. This low flow rate was designed to simulate flow conditions expected in the micropore domain of the intact saprolite. The primary experimental variable is the ethanol concentration in the groundwater feed solution and is set at $0,1.0$ and 10 $\mathrm{mM}$ ethanol (each in duplicate). Nitrate, iron(III), uranium(VI), and sulfate all appear to be reduced within the column regardless of the supplied concentration of ethanol (i.e., all columns appear to have similar biologic activity). The invariance with respect to supplied ethanol could be due to sufficient background organic matter in the sediments and/or to the diffusion of $\mathrm{H}_{2}(\mathrm{~g})$ from the anaerobic chamber atmosphere into the columns. The chamber atmosphere has since been changed from $95: 5 \% \mathrm{~N} 2: \mathrm{H} 2$ to $100 \% \mathrm{~N} 2$ to differentiate these possible effects. These column experiments will continue in the beginning of FY07. At the conclusion of these experiments, the columns will be deconstructed and the sediments subjected to a variety of detailed characterizations of both the microbial community, the mineralogy, and the long-term stability of the immobilized uranium. U LIII-edge EXAFS measurements will also be made on these sediments at the MRCAT/EnviroCAT insertion device beam line at the Advanced Photon Source.

\section{Information Access:}

Listed below are only our most recent publications from the last year of effort divided into those Published, In Press, In Review and In Preparation. 
$\underline{\text { Published }}$

Jeon, B.H., B.A. Dempsey, W.D. Burgos, M.O. Barnett and E.E. Roden. 2005. Chemical reduction of U(VI) at the solid-water interface using natural and synthetic iron(III) oxides. Environmental Science \& Technolology. 39:5642-5649.

Tuntoolavest, M., and W.D. Burgos. 2005. Anaerobic Phenol Oxidation by Geobacter metallireducens Using Various Electron Acceptors. Environmental Engineering Science. 22:421-426.

Fang, Y. L., S. B. Yabusaki, and G. T. Yeh, 2005. A general simulator for reaction-based biogeochemical processes. Computers and Geosciences 32:64-72.

Park, B., and B.A. Dempsey. 2005. Heterogeneous Oxidation of Fe(II) on Ferric Oxide at Neutral $\mathrm{pH}$ and a Low Partial Pressure of O2. Environmental Science \& Technolology. 39:6494-6500.

$\underline{\text { In Press }}$

Stone J.J., W.D. Burgos, R.A. Royer and B.A. Dempsey. 2006. Impact of Zinc on Biological $\mathrm{Fe}(\mathrm{III})$ and $\mathrm{NO}_{3}{ }^{-}$Reduction by Shewanella putrefaciens $\mathrm{CN} 32$. Environmental Engineering Science.

Stone J.J., W.D. Burgos, R.A. Royer and B.A. Dempsey. 2006. Zinc and Manganese Inhibition of Biological Hematite Reduction. Environmental Engineering Science.

Burgos, W.D, J.M. Senko, B.A. Dempsey, E.E. Roden, J.J. Stone, K.M. Kemner and S.D. Kelly. 2006. Soil Humic Acid Decreases Biological Uranium(VI) Reduction by Shewanella putrefaciens CN32. Environmental Engineering Science.

Jang, J.H., B.A. Dempsey and W.D. Burgos. 2006. Solubility of Schoepite: Comparison and Selection of Complexation Constants for U(VI). Water Research.

Suk, H. and G.T. Yeh, 2006. Three-dimensional three-phase flow simulations using the Lagragian-Eulerian approach with adaptively zooming and peak/valley capturing scheme (LEZOOMPC). ASCE Journal of Hydrologic Engineering.

Chen, C.W., G.T. Yeh, W.D. Burgos and M.L. Minyard, 2006. A Systematic Approach to Uncovering Scale-Independent Rate Formulations for Bioreduction of Hematite in Sediments at a Field Site. Proc. XVI International Conference on Computational Methods in Water Resources (Binning, P., Engesgaard, P., Dahle, H., Gray, W.G., and Pinder, G., eds). CD. Copenhagen, Denmark, June 19-22, 2006.

In Review

Tan, H., O. Ezekoye, J. van der Schalie, M. Horn, A. Lakhtakia, J. Xu and W. Burgos. 2006. Biological Reduction of Nano-Engineered Iron(III) Oxide Sculptured Thin Films. Environmental Science \& Technology. Re-submitted with minor revisions.

Zhang, F., G.T. Yeh, J.C. Parker, S.C. Brooks, M.N., Pace, Y.J. Kim, and P.M. Jardine, 2006. A reaction-based paradigm to model three-dimensional reactive chemical transport in groundwater. Journal of Contaminant Hydrology.

Suk, H., and G.T. Yeh. 2006. Multiphase flow modeling with general boundary conditions and phase configuration changes using fractional flow approaches. ASCE Journal of Hydrologic Engineering. 
Suk, H., and G.T. Yeh. 2006. Particle tracking algorithm for the Lagrangian finite element method under transient conditions in multi-dimensions. International J. Numerical Methods in Engineering.

Roden, E. E. 2005. Geochemical and microbiological controls on dissimilatory iron reduction. Geoscience

In Preparation

Minyard, M.L., and W.D. Burgos. Hydrologic flow controls biologic iron(III) reduction in natural sediments. Environmental Science \& Technology.

Burgos, W.D., M.L. Minyard, B.A. Dempsey and G.T. Yeh. Reaction-Based Reactive Transport Modeling of Biological Iron(III) Reduction. Geochimica Cosmochimica Acta

Stone, J.J., W.D. Burgos, R.A. Royer and B.A. Dempsey. Impact of Natural Organic Matter on Zinc Inhibition of Hematite Bioreduction. Environmental Engineering Science.

Senko, J.M., W.D. Burgos, B.A. Dempsey, S.D. Kelly, K.M. Kemner, A. Dohnalkova and J.M. Zachara. Kinetics of U(VI) reduction control kinetics of U(IV) re-oxidation. Environmental Science \& Technology.

Dempsey, B.A., R. Kirkham, and W.D. Burgos. Complexation of Uranyl with Humic Acid as a Function of $\mathrm{Pco} 2$ and $\mathrm{pH}$. Water Research.

Jang, J-H., B.A. Dempsey, W.D. Burgos. Abiotic Reduction of U(VI) with Fe(II) in the Presence of Hydrous Ferric Oxide (HFO) and Hematite plus Natural Organic Matter (NOM): Sorption, Reduction, and Transformation. Water Research.

Jang, J-H., B.A. Dempsey, W.D. Burgos. Sorption of U(VI) in the Presence of Hydrous Ferric Oxide and Hematite. Environmental Science \& Technology.

Jang, J-H., B.A. Dempsey, W.D. Burgos. Apparent Solubility of Hematite and Implications for Interfacial Reactions. Environmental Science \& Technology

Jang, J-H., B.A. Dempsey, W.D. Burgos. Similarity of Surface Reactivities of Hydrous Ferric Oxide and Hematite: Solubility, Sorption, Oxidation-Reduction Reactions. Environmental Science \& Technology

Dempsey, B.A., Ditto, M.A., Burgos, W.D., and Jang, J-H. Sorption of Uranyl onto Aluminum Oxides. Water Research. 